\title{
The Outcome of pregnancies obtained after IVF compared to spontaneous pregnancies at the Gynecological Endoscopic Surgery and Human Reproductive Teaching Hospital (GESHRTH)
}

\author{
Etienne Belinga ${ }^{1,2 *}$, Claude Cyrille Noa Ndoua ${ }^{1,2}$, Fabiola Nyebe ${ }^{2}$, Esther Voundi Voundi ${ }^{1,3}$, Michel Toukam ${ }^{1,3}$, Vanina Ngono ${ }^{2}$, Nathalie \\ Massin $^{4,5}$, Clément Jimenez ${ }^{6}$ and Jean Marie Kasia ${ }^{1,2}$ \\ ${ }^{1}$ Gynecological Endoscopic Surgery and Human Reproductive Teaching Hospital, Cameroon \\ ${ }^{2}$ Department of Obstetrics and Gynaecology, Faculty of Medicine and Biomedical Sciences, The University of Yaoundé I, Cameroon \\ ${ }^{3}$ Department of Microbiology, Parasitology, Haematology and Infectious Diseases, Faculty of Medicine and Biomedical Sciences, The University of Yaoundé I, \\ Cameroon \\ ${ }^{4}$ Intercommunal Hospital Centre of Creteil, Cameroon \\ ${ }^{5}$ University of Paris Descartes, Faculty of Medicine, Cameroon \\ ${ }^{6}$ University Hospital Centre Bordeaux, Cameroon
}

\begin{abstract}
Background: With the advent of Assisted Reproduction Technology, management of infertility amongst couples has remarkably evolved. Despite this great leap, with an increase in the rate of fertilization, few pregnancies progress until birth. The objective of this study was to compare the evolution of pregnancies obtained after IVF to those obtained naturally.

Methodology: We carried out a descriptive cross-sectional study with retrospective and prospective data collection from August 1"st, 2016 to April 30, 2019. Our study had two groups of pregnant women, the spontaneous pregnancy group and the post-IVF pregnancy group. Sampling was consecutive and exhaustive. Sociodemographic, clinical and para-clinical variables were collected. The Chi-square and Fischer's exact tests were used to compare variables. The odds ratio was calculated to determine associations between variables. A p value of $<0.05$ was considered significant.

Results: A total of 350 pregnancies were included in the study which comprised of 250 spontaneous pregnancies and 100 pregnancies obtained after IVF. Women pregnant through IVF, had an increase in the probability of being; nulliparous (OR: 26.18; CI [11.20-61.22]; $\mathrm{p}=0.01$ ), primiparous (OR: 1.8; CI [1.12-2.88]; $\mathrm{p}<0.01$ ), having multiple pregnancies (OR: 4.95; CI [2.32-10.59]; $\mathrm{p}<0.01$ ) and first trimester vaginal bleeding (OR: 16.72; CI [9.36-29.86]; $<<0.01)$ as compared to spontaneous pregnancies. We also observed that IVF pregnancies were 3.31 times more likely to end in elective cesarean section at the time of delivery than spontaneous pregnancies (OR: 3.31; CI [1.95-5.70]; $\mathrm{p}<0.01$ ). Some of the obstetric and neonatal complications we studied had a comparable risk between the two groups without statistical significance.

Conclusion: IVF pregnancies have a higher risk of bleeding and miscarriage in the first trimester with a higher probability in resulting to an elective cesarean section at the time of delivery compared to spontaneous pregnancies.
\end{abstract}

\section{Introduction}

Infertility amongst couples carries a significant psychosocial impact and is nowadays considered a global public health problem. In Central Europe, its prevalence varies from 10 to $15 \%$ [1]. In Central Africa, Cameroon alone has a prevalence of 20 to $30 \%[2,3]$. The introduction of Assisted Reproduction Technology (ART) has greatly revolutionized the management of infertility amongst couples. However, despite the fact that there is a high fertilization rate with this procedure, few pregnancies progress until birth. The evolution of pregnancies resulting from ART is a current issue of concern. Many studies show an association between In Vitro Fertilization (IVF) and a significant risk of fetal, obstetric and neonatal complications. These are mainly bleeding and miscarriages in the first trimester, congenital malformations, hypertensive disorders, and prematurity. The main objective of this study was to compare the evolution of pregnancies obtained after IVF to those obtained naturally.

${ }^{*}$ Correspondence to: Etienne BELINGA, Obstetrician \& Gynecologist, Senior Lecturer, Department of Obstetrics and Gynecology, Faculty of Medicine and Biomedical Sciences, The University of Yaoundé I, Cameroon, E-mail: belingaetienne@yahoo.fr

Key words: IVF, pregnancy, vaginal bleeding, cesarean section

Received: November 12, 2019; Accepted: November 25, 2019; Published: November 28, 2019 
Belinga E (2019) The Outcome of pregnancies obtained after IVF compared to spontaneous pregnancies at the Gynecological Endoscopic Surgery and Human Reproductive Teaching Hospital (GESHRTH)

\section{Methodology}

We carried out a cross sectional, descriptive and analytical study with both retrospective and prospective data collection at the Gynaecological Endoscopic Surgery and Human Reproductive Teaching Hospital (GESHRTH). Our study extended over a period of 32 months. From August 1, 2016 to April 30, 2019. Sampling was consecutive and exhaustive after institutional authorization, and ethical committee approval to carry out the study. We had two groups of participants, the spontaneous pregnancy group and the post-IVF pregnancy group. All women who accepted to participate in the study signed a consent form. We included in our study, all patients who had a spontaneous pregnancy which was being followed up at the GESHRTH as well as all patients who had undergone an IVF procedure at the GESHRTH with a resultant pregnancy followed up at the GESHRTH or elsewhere. We excluded, all patients who had undergone IVF elsewhere as well as those whose information regarding the evolution of her pregnancy unknown.

\section{Data collection}

Data collection started by identifying patients who conceived spontaneously and where attending antenatal clinic at the GESHRTH as well as those who conceived after IVF by looking through the IVF and ANC register of the above institution. Collection of data was done with the use of a pre-tested, validated data sheet by consulting the patients' records and interview (one on one or by telephone) if additional information was needed. Information pertaining to the socio demographic characteristics of the patients, clinical and paraclinical data concerning evolution, complications and outcome of the pregnancy as well as the neonate were recorded. The sample size was calculated from a pilot study. The minimum number of patients needed was 100 post IVF pregnancies. One IVF pregnancy was matched to 2.5 spontaneous pregnancies, which gave a final sample size of 350 pregnancies.

\section{Statistical analysis}

The variables were compared using the Chi Square and Fischer's exact tests. The error threshold was set at $5 \%$ as statistically significant for each variable studied. The association between the variables was made using the Odds Ratio expressed with its confidence interval at $95 \%$. A p value of $<0.05$ was considered statistically significant.

\section{Results}

A total of 350 pregnancies (250 spontaneous pregnancies and 100 IVF pregnancies) were included in the study. The average age of IVF pregnant women group was $37 \pm 8$ years, while that of women with spontaneous pregnancies was $31 \pm 5$ years. The majority of pregnant women in our study population were married with $57.1 \%$ (81\% IVF pregnant women vs. $47.6 \%$ spontaneous pregnancy women) and worked in the public sector with $47.1 \%$ (55\% of IVF pregnant women vs. $44 \%$ spontaneous pregnancy women).

Women pregnant through IVF had an increase in probability of being nulliparous (OR: 26.18; CI [11.20-61.22]; $\mathrm{p}=0.01$ ) and primiparous (OR: 1.8; CI [1.12-2.88]; $\mathrm{p}<0.01)$ and Multiple pregnancies were more likely to occur after IVF than spontaneous pregnancies (OR: 4.95; CI [2.32-10.59]; $\mathrm{p}<0.01$ ) as highlighted in Table 1.

The most common obstetric complication was vaginal bleeding in the first trimester that was 16.72 times more likely of occurring in IVF pregnant women than in spontaneous pregnant women (OR: 16.72; CI [9.36-29.86]; $\mathrm{p}<0.01$ ). The IVF pregnancy had 18.42 odds of bleeding in the first Trimester as illustrated in Table 2. This vaginal bleeding was the most likely cause of early miscarriages observed in our study with risk of early miscarriage multiplied by 5.34 in the IVF pregnancy group as compared to the spontaneous pregnancy group (OR: 5.34; IC [2.68-11.06]; $\mathrm{p}<0.01)$ as well as the main reason for long prenatal hospitalizations as shown in Table 3.

\section{The Outcome}

We observed that IVF pregnancies were more likely to end in an elective cesarean section at the time of delivery as compared to spontaneous pregnancies (OR: 3.31; CI [1.95-5.70]; $\mathrm{p}<0.01$ ). Some of the obstetric and neonatal complications we studied had a comparable risk between the two groups without statistical significance. These were mainly hypertensive disorders, gestational diabetes, placental insertion abnormalities, postpartum bleeding, prematurity, neonatal asphyxia, macrosomia and congenital malformations visible in these newborns.

Table 1. Obstetrical profile of participants and pregnancy characteristics

\begin{tabular}{|c|c|c|c|c|c|c|}
\hline \multicolumn{2}{|c|}{ Variables } & \multirow{2}{*}{$\begin{array}{c}\text { Total (\%) } \\
91(26)\end{array}$} & \multirow{2}{*}{$\begin{array}{c}\text { IVF } \\
\text { N (\%) } \\
41(41)\end{array}$} & \multirow{2}{*}{$\begin{array}{c}\text { Spontaneous n (\%) } \\
50(20)\end{array}$} & \multirow{2}{*}{$\begin{array}{c}\text { OR } \\
\text { [CI 95\%] } \\
2.78[1.68-4.61]\end{array}$} & \multirow{2}{*}{$\begin{array}{r}\text { Pvalue } \\
<0.01\end{array}$} \\
\hline Grovidity & 1 & & & & & \\
\hline 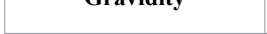 & $\geq 2$ & $259(74)$ & $59(59)$ & $200(80)$ & $0.36[0.22-0.59]$ & $<0.01$ \\
\hline \multirow{3}{*}{ Parity } & Nullipara & $50(14.3)$ & $43(43)$ & $7(2.8)$ & $26.18[11.20-61.22]$ & $<0.01$ \\
\hline & Primipara & $136(38.9)$ & $49(49)$ & $87(34.8)$ & $1.8[1.12-2.88]$ & 0.014 \\
\hline & Multipara & $164(46.9)$ & $8(8)$ & $156(62.4)$ & $0.052[0.02-0.11]$ & $<0.01$ \\
\hline \multirow[t]{6}{*}{$\begin{array}{c}\text { History of Pelvic } \\
\text { surgery }\end{array}$} & Total & $121(34.6)$ & $59(59)$ & $62(24.8)$ & $4.36[2.67-7.12]$ & $<0.01$ \\
\hline & Myomectomy & $39(11.1)$ & $27(27)$ & $12(4.8)$ & $7.34[3.54-15.20]$ & $<0.01$ \\
\hline & Cœlioscopy & $36(10.3)$ & $27(27)$ & $9(3.7)$ & $9.90[4.46-22.11]$ & $<0.01$ \\
\hline & Salpingectomy & $20(5.7)$ & $14(14)$ & $6(2.4)$ & $6.62[2.47-17.78]$ & $<0.01$ \\
\hline & Polypectomy & $6(1.7)$ & $5(5)$ & $1(0.4)$ & 13.11[1.51-16.32] & 0.003 \\
\hline & Appendicitis & $8(2.3)$ & $3(3)$ & $5(2)$ & $1.52[0.6-6.46]$ & 0.572 \\
\hline \multirow{2}{*}{ Type of pregnancy } & Single & $319(91.1)$ & $80(80)$ & $239(95.6)$ & $0.18[0.08-0.40]$ & $<0.01$ \\
\hline & Multiple & $31(9.9)$ & $20(20)$ & 11(4.4) & $4.95[2.32-10.59]$ & 0.003 \\
\hline \multirow{3}{*}{$\begin{array}{l}\text { Localization } \\
\text { pregnancy }\end{array}$} & Intra uterine & $347(99.1)$ & $98(98)$ & $249(99.6)$ & $0.13[0.13-1.26]$ & 0.390 \\
\hline & Extra-uterine & $3(0.9)$ & $2(2)$ & $1(0.4)$ & $5.08[1.04-5.96]$ & 0.141 \\
\hline & Heterotopic & $1(0.3)$ & 1(1) & - & - & 0.113 \\
\hline
\end{tabular}


Belinga E (2019) The Outcome of pregnancies obtained after IVF compared to spontaneous pregnancies at the Gynecological Endoscopic Surgery and Human Reproductive Teaching Hospital (GESHRTH)

Table 2. Antenatal complications of participants

\begin{tabular}{|c|c|c|c|c|c|}
\hline Variables & Total n (\%) & $\begin{array}{c}\text { IVF } \\
\text { n (\%) }\end{array}$ & Spontaneous n (\%) & OR [CI 95\%] & $P$ value \\
\hline Vaginal bleeding & $92(42)$ & $91(91)$ & $56(22,4)$ & $16,72[9,36-29,86]$ & $<0,01$ \\
\hline First trimester bleeding & $86(93.5)$ & 64(97) & $22(85)$ & $18,42[10,12-33,52]$ & $\mathbf{0 , 0 1}$ \\
\hline Early Abortion & $34(73.9)$ & $31(91.2)$ & $3(25)$ & $5.34[2.68-11.06]$ & $<0.01$ \\
\hline Rupture of membranes & $31(8.9)$ & $4(4)$ & & & \\
\hline Threatened preterm delivery & $26(7,4)$ & $4(4)$ & $22(8,8)$ & $0,43[0,15-1,28]$ & 0,122 \\
\hline Gestational hypertension & $15(4,3)$ & $5(5)$ & $10(4)$ & $1,26[0,42-3,79]$ & 0,676 \\
\hline Chronic Hypertension & $9(2,6)$ & $4(4)$ & $5(2)$ & $2,04[0,54-7,76]$ & 0,286 \\
\hline Pre-eclampsia & $6(1,7)$ & $3(3)$ & $3(1,2)$ & $2,55[0,51-12,88]$ & 0,241 \\
\hline Gestational Diabete & $4(1,1)$ & $2(2)$ & $2(0,8)$ & $2,53[0,35-18,21]$ & 0,340 \\
\hline Placenta abruptio (RPH) & $5(1,4)$ & - & $5(2)$ & - & 0,154 \\
\hline Placenta prævia & $4(1,1)$ & $1,2(3)$ & $1(1,2)$ & $0,85[0,83-8,09]$ & 0,874 \\
\hline Placenta accreta & $2(0,6)$ & - & $2(0,8)$ & - & 0,370 \\
\hline Hyperemesis gravidarum & $5(1,4)$ & $2(2)$ & $3(1,2)$ & $1,68[0,28-10,2]$ & 0,569 \\
\hline Malaria & $40(11,4)$ & $5(5)$ & $35(14)$ & $0,32[0,12-0,85]$ & 0,017 \\
\hline Vaginal infections & $16(4,6)$ & $1(1)$ & $15(6)$ & $0,16[0,21-1,21]$ & 0,043 \\
\hline Urinary tract infection & $15(4,3)$ & $2(2)$ & $13(5,2)$ & $0,37[0,82-1,68]$ & 0,182 \\
\hline Hospitalization in the $1^{\text {st }}$ Trimester & $113(32.3)$ & $99(99)$ & $14(5.6)$ & $16.7[16.5-28.63]$ & $<0.01$ \\
\hline Hospitalization in the $3^{\text {rd }}$ Trimester & $72(20.6)$ & $40(40)$ & $32(12.8)$ & $4.54[2.63-7.83]$ & $<0.01$ \\
\hline
\end{tabular}

Table 3. Multivariate analysis with logistic regression

\begin{tabular}{|c|c|c|}
\hline Outcome of pregnancies & Odds ratio & $\mathbf{9 5 \%}$ CI \\
\hline Gravidity & 0,44 & $0,24-0,80$ \\
\hline Nulliparity & 0,04 & $0,06-0,34$ \\
\hline Primiparity & 0,66 & $0,40-1,71$ \\
\hline Past history of pelvic surgery & 0,85 & $0,52-1,39$ \\
\hline Multiple pregnancy & 2,36 & $1,70-7,92$ \\
\hline Vaginal bleeding in 1st Trimester & 1,92 & $1,02-4,14$ \\
\hline Early abortion & 2,22 & $2,04-8,71$ \\
\hline Cesarean section delivery & 2,41 & $1,10-5,28$ \\
\hline Hospitalization & 2,02 & $1,19-3,44$ \\
\hline
\end{tabular}

\section{Discussion}

Some studies found a higher proportion of nullipara women were undergoing IVF in comparison to that found in our study [4]. This discrepancy can be explained by the limited access to specialized structures in assisted reproductive technology (ART) in our context [5]. The obstetric profile of these patients could further explain the different maternal complications (i.e. hypertensive disorders, gestational diabetes etc.) and perinatal complications (membrane rupture, prematurity and congenital malformations) very often found in the literature, which is often associated with ART [6-8].

Concerning the proportion of multiple pregnancies, other authors found a higher incidence of multiple pregnancies with ART compared to that of our study [9]. This could be explained by the reduction in the number of embryos transferred per procedure or better still confirm the fact that with time, the incidence of multiple pregnancies is dropping [10]. The most common complication for women undergoing ART was vaginal bleeding in our study; this finding has been corroborated by many authors throughout literature $[4,11,12]$. However, this complication is not specific to ART; it is common to pregnant women above 35 years of age regardless of the mode of conception [13]. Regarding the outcome of pregnancies, similar studies agree that most pregnancies gotten through IVF are more likely to end in a caesarian section $[9,11,14]$. This could be explained by the fact that most women who undergo ART are anxious about the outcome of their pregnancy [15] and as such are more likely to opt for the mode of delivery with less neonatal complications.
In conclusion, our studies show that IVF pregnancies have a higher risk of bleeding and miscarriage in the first trimester. In addition, they are more likely to end in a caesarian section.

\section{Disclosure of interest}

The authors report no conflict of interest.

\section{References}

1. Larsen U, Masenga G, Mlay J (2006) Infertility in a community and clinic-based sample of couples in Moshi, northern Tanzania. East Afr Med J 83: 10-17. [Crossref]

2. Leke RJ, Oduma JA, Bassol-mayagoitia S, Maria A, Grigor KM, et al. (1993) Regional and geographical variations in infertility: effects of environmental, cultural, and socioeconomic factors. Environ Health Perspect 101 Suppl 2: 73-80. [Crossref]

3. Nana PN, Wandji JC, Fomulu JN, Mbu RE, Leke RJ, et al. (2011) Aspects psychosociaux chez patients infertiles à la maternite principale de l'hopital central de yaoundé, Cameroun. Clin Mother Child Heal 8: 1-5.

4. Luke B, Mph S, Mph DG, Cabral H, Stern JE, et al. (2017) Pregnancy, birth, and infant outcomes by maternal fertility status: the Massachusetts Outcomes Study of Assisted Reproductive Technology. Am J Obstet Gynecol 217: 327.e1-327.e14.

5. Meka Ngo Um (2016) Connaissances, Attitudes et Pratiques des Femmes en Désir d' Enfant Vis-à-vis de 1' Infertilité à 1' Hôpital Gynéco- Obstétrique et Pédiatrique de Yaounde. Health Sci Diseases 17: 41-46.

6. Zhu L, Zhang Y, Liu Y, Zhang R, Wu Y, et al. (2016) Maternal and Live-birth Outcomes of Pregnancies following Assisted Reproductive Technology: A Retrospective Cohort Study. Nat Publ Gr 1-11.

7. Sabban H, Zakhari A, Patenaude V, Tulandi T (2017) Obstetrical and perinata morbidity and mortality among in-vitro fertilization pregnancies: a population-based study. Arch Gynecol Obstet 296: 107-113. [Crossref]

8. Qin J, Ph D, Liu X, Sheng X, Wang H, Gao S, et al. (2016) Assisted reproductive technology and the risk of pregnancy-related complications and adverse pregnancy outcomes in singleton pregnancies: a meta-analysis of cohort studies. Fertil Steril 105: 73-85. [Crossref]

9. Egbe TO, Sandjon G, Ourtchingh C, Simo A, Priso EB, et al. (2016) In-vitro fertilization and spontaneous pregnancies: matching outcomes in Douala, Cameroon. Fertil Res Pract 2: 1-8. [Crossref]

10. All BK, Olausson PO (2011) Maternal and child outcome after in vitro fertilization - a review of 25 years of population-based data from Sweden. Acta Obstetricia et Gynecologica Scandinavica 90: 494-500. [Crossref]

11. Ezechi OC, Ndububa VI, Loto OM, Ezeobi PM, Kalu BKE (2008) Pregnancy, obstetric and neonatal outcome after assisted reproduction in Nigerians. J Matern Fetal Neonatal Med 21: 261-266. [Crossref] 
Belinga E (2019) The Outcome of pregnancies obtained after IVF compared to spontaneous pregnancies at the Gynecological Endoscopic Surgery and Human Reproductive Teaching Hospital (GESHRTH)

12. Farhi A, Reichman B (2013) Maternal and neonatal health outcomes following assisted reproduction. Reprod Biomed Online 26: 454-461. [Crossref]

13. Ziadeh SM (2002) Maternal and perinatal outcome in nulliparous women aged 35 and older. Gynecol Obstet Invest 11192: 6-10. [Crossref]
14. Shevell T, Malone FD, Vidaver J, Porter TF, Luthy DA (2005) Assisted reproductive technology and pregnancy outcome. Obstet Gynecol 106: 1039-1045. [Crossref]

15. Gdańska P, Drozdowicz-jastrzębska E, Grzechocińska B, Radziwoń-zaleska M, Węgrzyn P, et al. (2017) Anxiety and depression in women undergoing infertility treatment. Ginekologia Polska 88: 109-112. [Crossref]

Copyright: (C2019 Belinga E. This is an open-access article distributed under the terms of the Creative Commons Attribution License, which permits unrestricted use, distribution, and reproduction in any medium, provided the original author and source are credited. 